\title{
كفاءة الخدمات الصحية في مدينة الزبير وأثرها على السكان
}

\section{دراسة في جغرافية المدن}

م·م وسن نوشي محمد

جامعة واسط

ملخص البحث

الخدمات الصحية هي مجموعة من الخدمات الوقائية التي إذا تم تطبيقها تجنب الأفراد الإصابة بالعديد

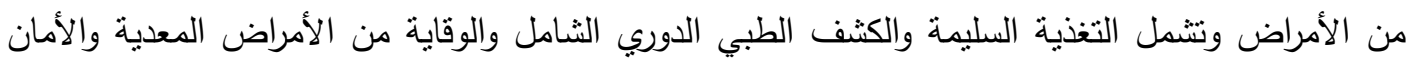
والإسعافات الأولية والعناية بالجسم والمحافظة عليه للأفراد المعاقين والأسوياء وتوفير الأجهزة والأدوات التعويضية للأفراد المعاقين والخدمات العلاجية ، وتعتبر الخدمات الصحية إحدى الاهتمامات التي تمنحها الدول الكثير من رعايتها وعنايتها لما لها عظيم الأثر في الاهتمام بصحة الإنسان والعناية بهم والمحافظة العانة

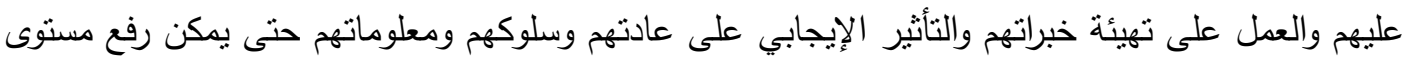

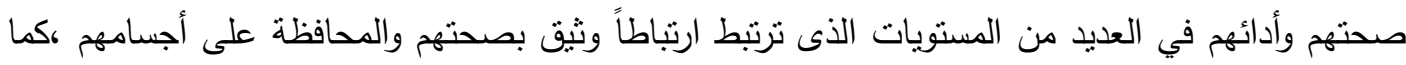

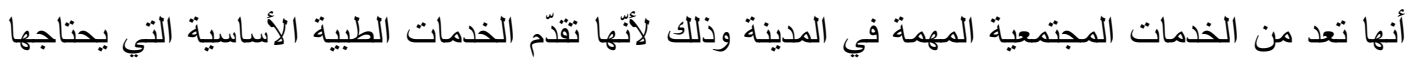
سكان هذه الددينة ، وتواجه معظم الددن العراقية ومنها منطقة الدراسة عدداً من المشاكل والتحديات، المتمثلة

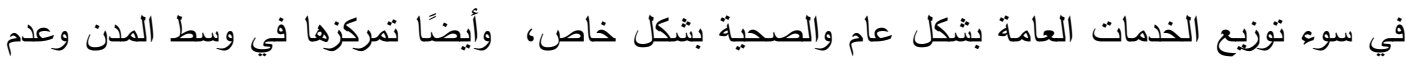
مراعاة المعايير التخطيطية في توزيعها بما يتواكب مع الزيادة السكانية والتوسع العمراني واحتياجات السكان

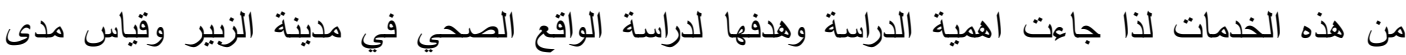

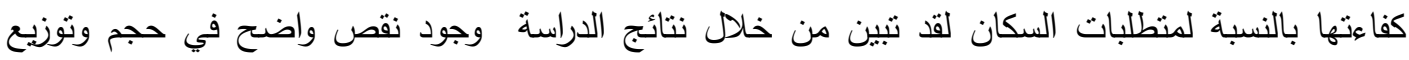
الخدمات المقدمة إلى سكان الددينة في مركز مدينة الزبير، وهذا النقص ليس فقط نتيجة النقص في وجودها

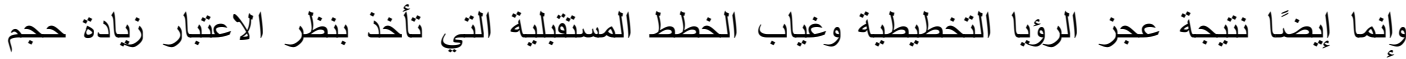
سكان المدينة من خلال النمو الطبيعي للمدينة. 


\begin{abstract}
Health Services is a set of preventive services, which if applied to avoid individuals infection with many diseases and include a medical examination UPR and prevention of infectious and safety, first aid and care of the body and maintain it for individuals with disabilities and without disabilities and to provide instruments and tools compensatory for individuals with disabilities and therapeutic services diseases, proper nutrition, and considers health services one of the concerns which granted states a lot of the care and attention because of its great impact on concern for human health and take care of them and maintain them and work to create an experience and positive impact on their habit, behavior and knowledge so that it can raise the level of their health and their performance at many levels, which linked closely to their health and the preservation of their bodies, as longer as important community services in the city and because they offer basic medical services needed by the residents of this city, most Iraqi cities are facing, including the study area a number of problems and challenges, of poor public services distribution in general and health in particular, and also pinned down in the center of cities and failure to observe

Planning standards in their distribution to cope with the population growth, urbanization, and population needs these services so came the importance and purpose of the study to examine the health situation in the town of Zubair and measure the efficiency for the requirements of the population has been shown by the results of the study and there is a clear lack of size and distribution services provided to residents of the city Zubair in the city center, and this shortage is not only the result of a lack of presence, but also as a result of the vision planning deficit and the absence of future plans that take into account the increase in the size of the city's population through natural growth of the city
\end{abstract}


تمثل الصحة حالة من الرفاهية البدنية والذهنية والاجتماعية وليس مجرد غياب المرض أو إصابة

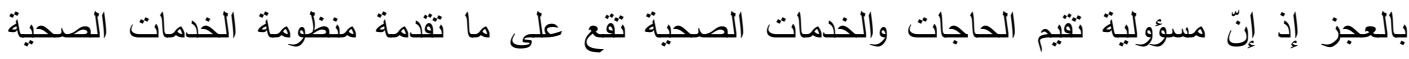

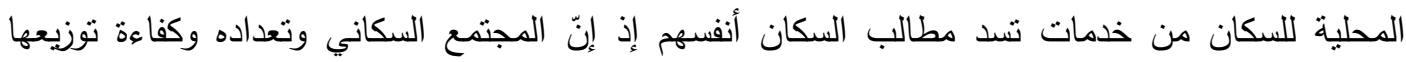
الجغرافي وطبيعة المراكز الخدمية التي تقدمها وكل ذلك مرتبط بطبيعة الأطر الثقافية والسلوكية والاجتماعية وحتى البيئية وبحسب هذه التركيبة غير المنسجمة بين المنظومات الخدمية والمجتمعية تتوقف قابلية هذه ولهية

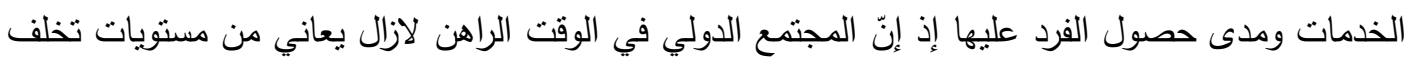

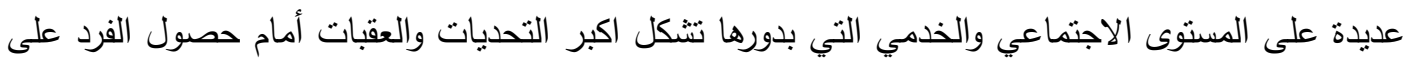
اغلب حاجاته الصحية الملائمة (1).

ازداد الاهتمام بالخدمة الصحية العامة منذ عقد الثمانينات في البلدان المتقدمة والنامية على حدا السوء ،

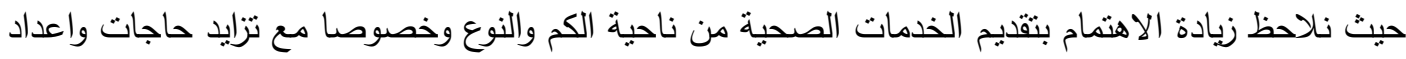

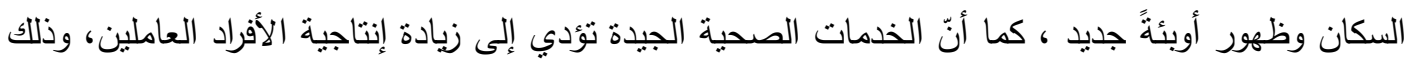

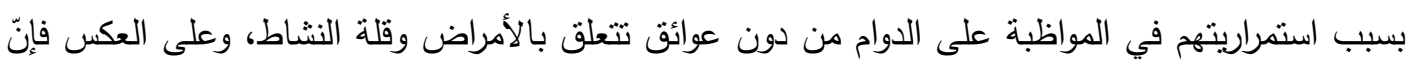

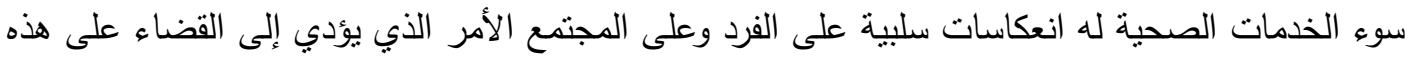

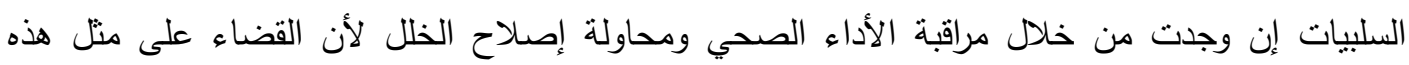
السلبيات يعد عملية هامة ذات مردودية عالية على عملية التتمية(؟).

فضلًا على أنّ الاهتمام بجودة الخدمات تكافئ أو قد تفوق الاهتمام بجودة السلع في الكثير من بلدان العالم

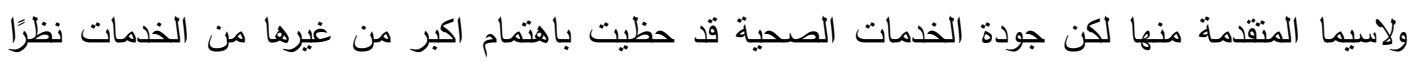

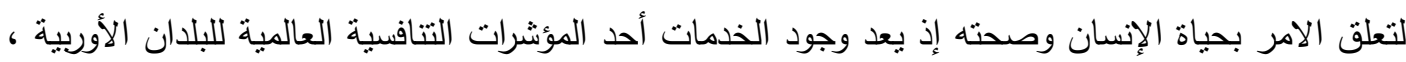

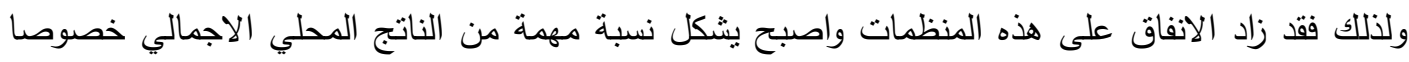

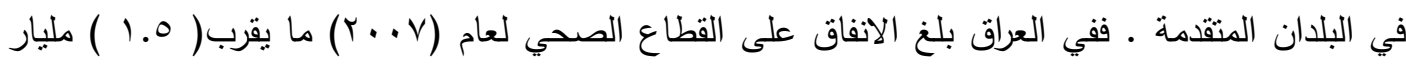

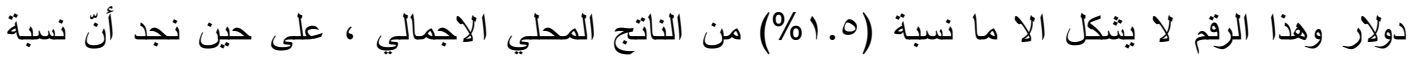

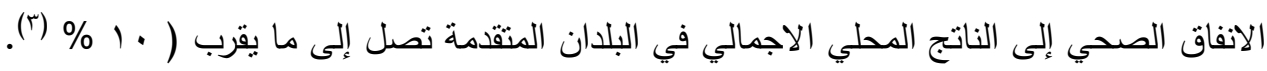

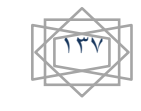




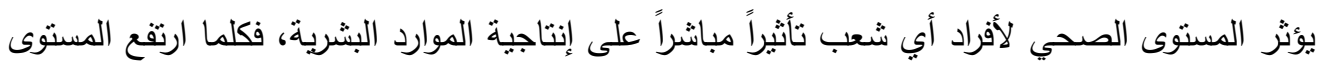

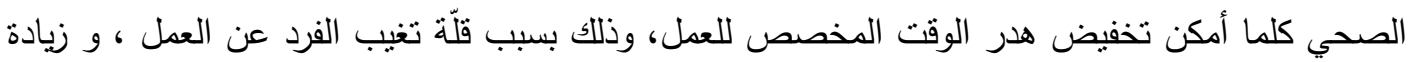

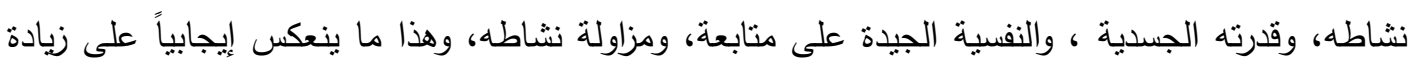

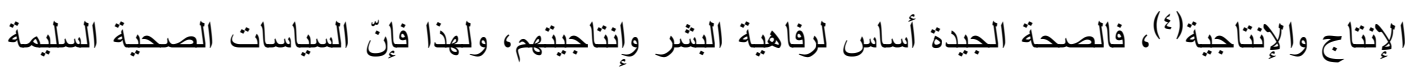

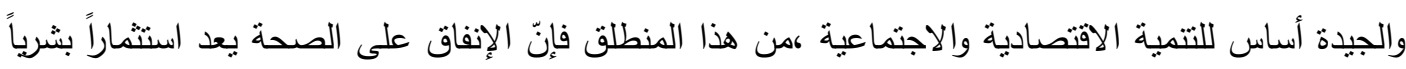

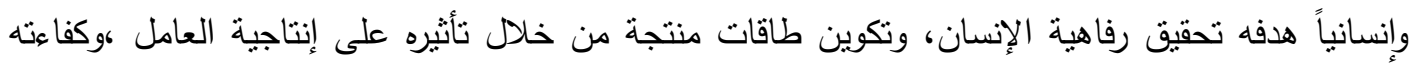

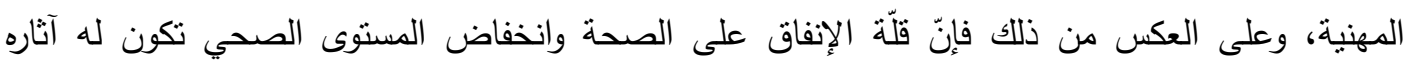

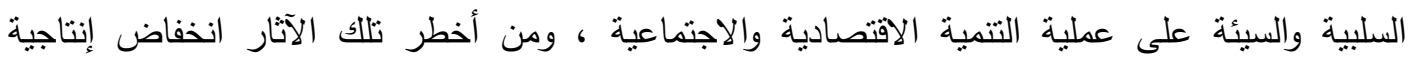

العاملين بسبب عدم تمكنهم من العمل المستمر وكثرة تغييهم عن العمل (0).

$$
1
$$

\section{مشكلة البحث:}

تُعد الخدمات التي تقدمها الحكومة المحلية في المحافظة بشكل عام ومركز قضاء الزبير بشكل

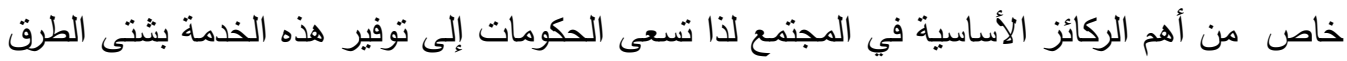

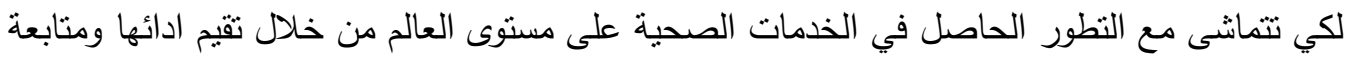

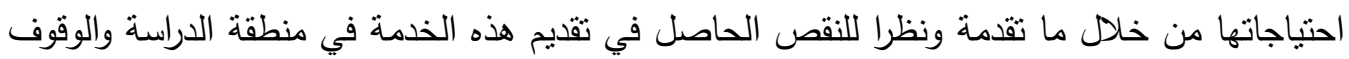

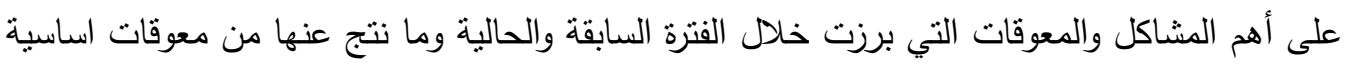
ظهرت الدراسة لكي تقف على بعض المشاكل عسى ان نأخذ بها السلطات المعنية لمعالجة المشكلة

$$
\text { أهداف البحث: }
$$

الهدف الرئيس لهذه الدراسة هو دراسة الواقع الصحي وقياس مدى كفاءته بالنسبة لمنطلبات السكان

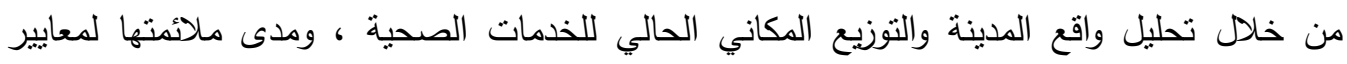
التخطيط الحضري التي تلبي احتباجات المجتمع المحلي في مدينة الزبير

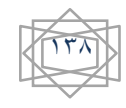


لقد أصبحت الصحة من الأمور الاكثر أهمية في مجال التتمية، وذللك بوصفها من العوامل التي تسهم في تحقيق التتمية وأحد مؤشراتها، فلا بمكن تحقيق التتمية بدون سكان أصحاء وذللك لأنّ جوانب الخدمة الصحية تؤثر تأثيراً كبيراً على النمو والتتمية بمجالاتها شتى، لذا برزت أهميتها من خلال ما تقدم لكي تتماثى مع التطور الحاصل على مستوى العالم فرضية الدراسة

تقترض هذه الدراسة من خلال التشالأت التالية :

1- هل الخدمات الموجودة لتتناسب مع إعداد السكان وأن نوزيع الوحدات الصحية عادل داخل المدينة. r- هل الخدمات الصحية تتوزع بشكل منكافئ مع توزيع السكان. r- هل هنالك تباين مكاني في الخارطة الصحية للخدمات الموزعة بالمحافظة من مستلزمات بشرية ومادية يجب تلافيها. منهجية البحث: :

اتبعت الدراسة في منهجيتها المنهج الوصفي والمنهج التحليلي بالارتكاز على نتائج التعداد السكاني الذي قام به الجهاز المركزي للإحصاء في عام ، 199V ونتائج المسح الميداني الثامل الذي قام به الباحث للخدمات الصحية في منطقة الدراسة. 


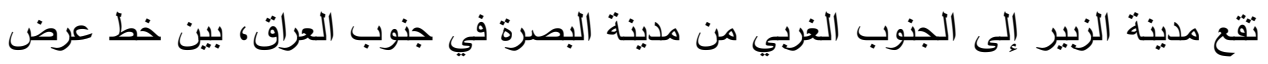
N

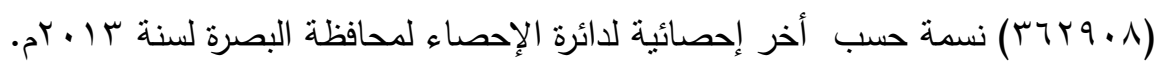

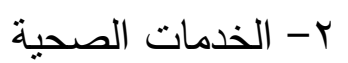

ومن خلال ملاحظة جدول (1) وخارطة (r) والثكل (1) (1) بلغت المساحة الفعلية المشغولة

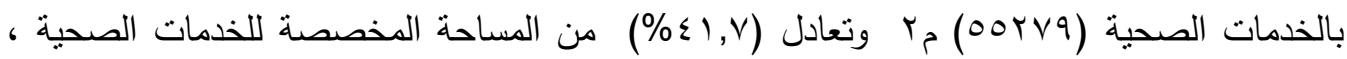

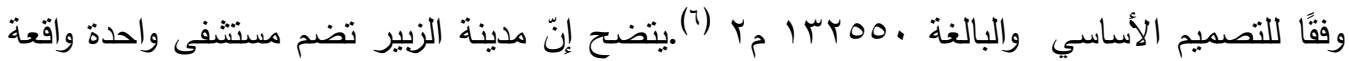

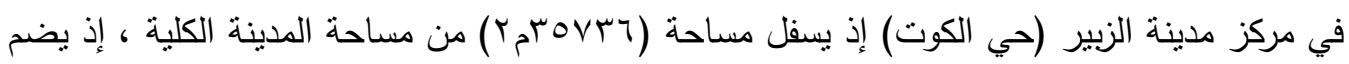

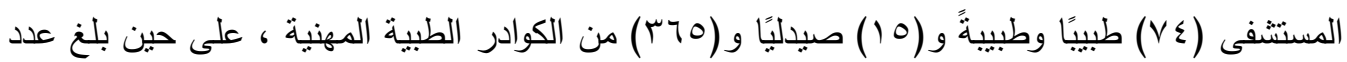
الأسرة צr سريرًا. 
خارطة (1)

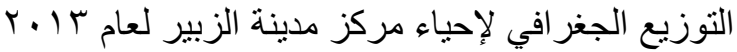

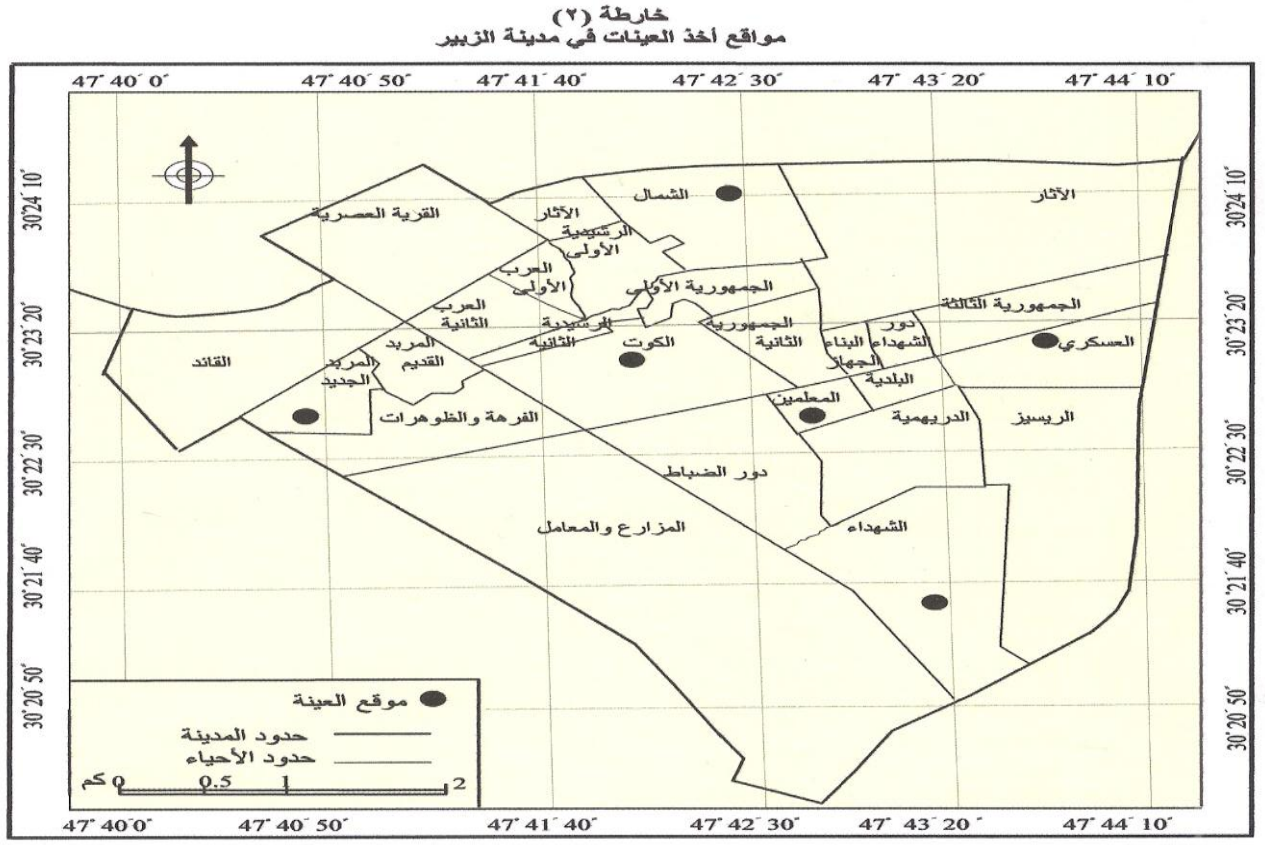

المصدر : من عمل الباحثة اعتماداً على ، مديرية بلدية قضاء الزبير ، الثعبة الفنية ،خارطة مدينة الزبير ، • 1 • م 
خارطة (r) (ب) (ب) (ب)

$\star$

التوزيع الجغر افي للمركز الصحية في مدينة الزبير

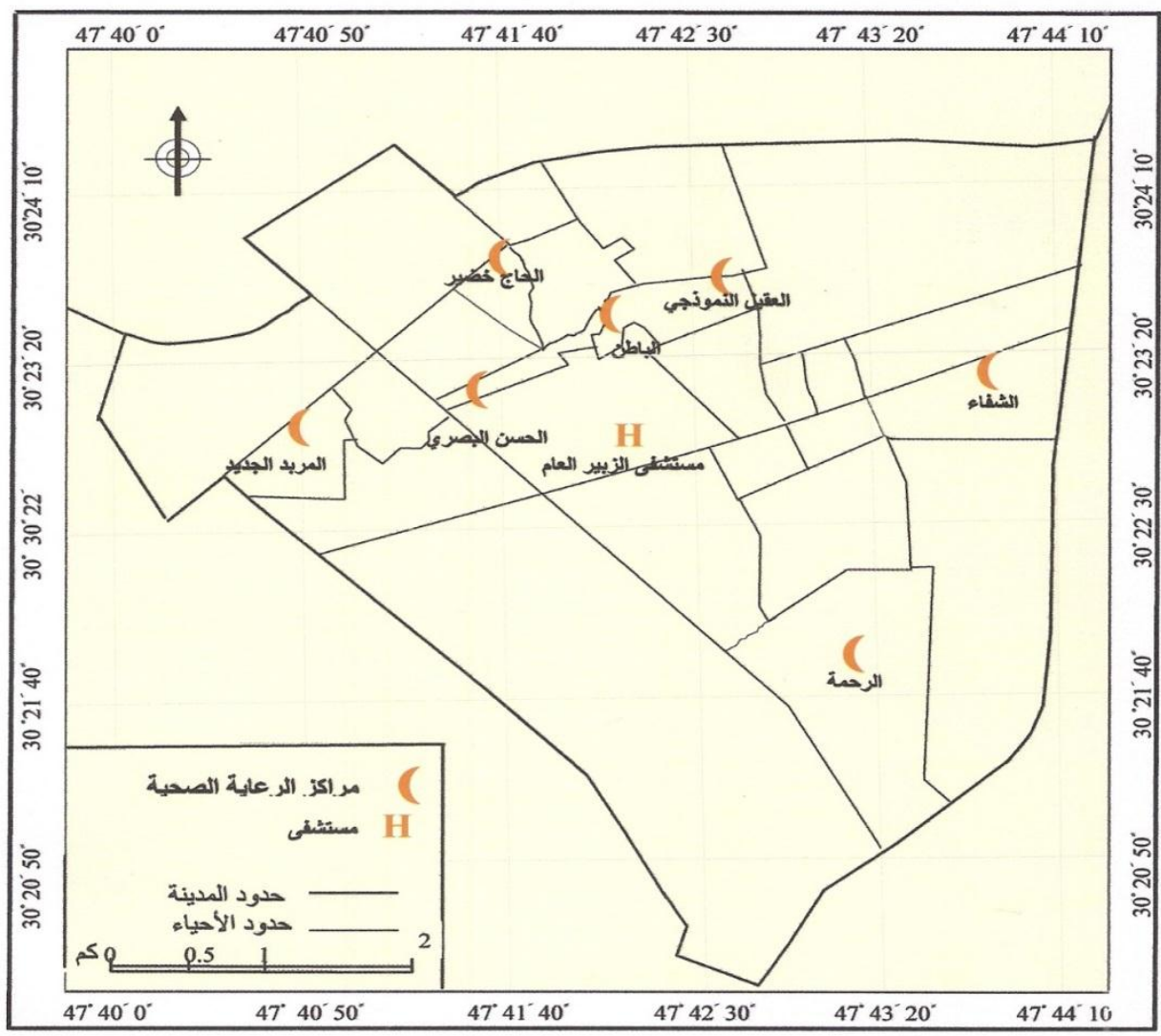

المصدر: من عطل الباحث اعتمادا" على الدرامة الميدانية ، وقطاع الزبير لر عاية الصحية الأولية.

* ثمة مؤسسات صحية أخرى في المدينة كالعيادات الخاصة والمجمعات الطبية .

المصدر : من عمل الباحثة اعتماداً على ، مديرية بلدية قضاء الزبير ، الثعبة الفنية ،خارطة مدينة 
جدول (1)

مجلـــة كليـــة التربيــة

عدد المستشفيات والأطباء والصيادلة والكوادر الطبية المهنية والأسرة في مدينة الزبير لسنة با. ب

\begin{tabular}{|c|c|c|c|c|c|c|}
\hline الأسرة & الكوادر الطبية المهنية & صيادلة & الأطباء & المساحة / r & الموقع & اسم المستشفى \\
\hline TYT & ס & 10 & $V \varepsilon$ & ToVry & حي الكوت & الزبير العام \\
\hline
\end{tabular}

الصدر : عمل الباحثة الميداني بالاعتماد على:

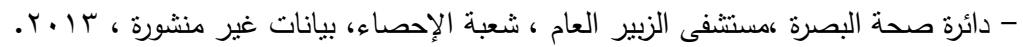

جدول (r)

عدد المركز الصحية والأطباء والصيادلة والكوادر الطيية المهنية والسكان لكل مركز والمساحة والنسبة المئوية لهما في مدينة الزبير

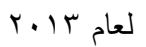

\begin{tabular}{|c|c|c|c|c|c|c|c|c|c|}
\hline الكوادر & الصيادلة & الأطباء & اللسئوية & عدد السكان & المئوية & مساحة/ & الموقع & المركز & ت \\
\hline דצ & 1 & $\wedge$ & $1 \varepsilon$ & 「یו1 & $1 \pi$ & ro.. & الرشيدية/1 & الباطن & 1 \\
\hline YT & 。 & 9 & 14 & $r \leqslant 0 T^{\prime}$ & 1. & $r \ldots$ & الجمهورية & العقيل & r \\
\hline rT & 1 & 0 & 11 & 纟TVAY & r) & $\varepsilon \cdot \varepsilon r$ & محلة العرب & خضير & $r$ \\
\hline IV & 1 & $r$ & 1. & TOYTE & $\pi$ & ro.. & محلة العرب & البصري & $\varepsilon$ \\
\hline ro & r & 7 & 10 & TQYrT & 1. & $r \ldots$ & حي المربد & المربد & 。 \\
\hline$r$. & 1 & 7 & 17 & EYQTA & r. & $\varepsilon \ldots$ & العسكري & الثفاء & 7 \\
\hline
\end{tabular}


العـــــــد الرابع والعشرون

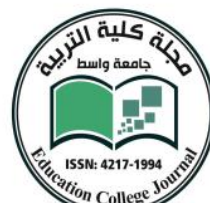

\begin{tabular}{|c|c|c|c|c|c|c|c|c|c|}
\hline 17 & 7 & 0 & $1 \leq$ & rNrrq & ir & ro.. & حي الشهداء & الرحمة & v \\
\hline 10r & IV & $\varepsilon r$ & $1 \ldots$ & $r 701 \ldots$ & $1 \ldots$ & $190 \leqslant r$ & V & v & المجموع \\
\hline
\end{tabular}

المصدر : عمل الباحثة الميداني بالاعتماد على

- دائرة صحة البصرة ، قطاع الزبير ، مركز العقيل النموذجي ، شعبة الإحصاء، بيانات غير منشورة ، با ـ r.

شكل (1)

يمنل عدد الأطباء والصيادلة والكوادر الطبية المهنية و عدد السكان والمساحة والنسبة المئوية لهما في مدينة

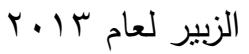

(1) شكل

عدد الاطباء والصيادلة والكوادر الطبية المهنية في مستثفى الزبير العام لعام ب ا ـ r

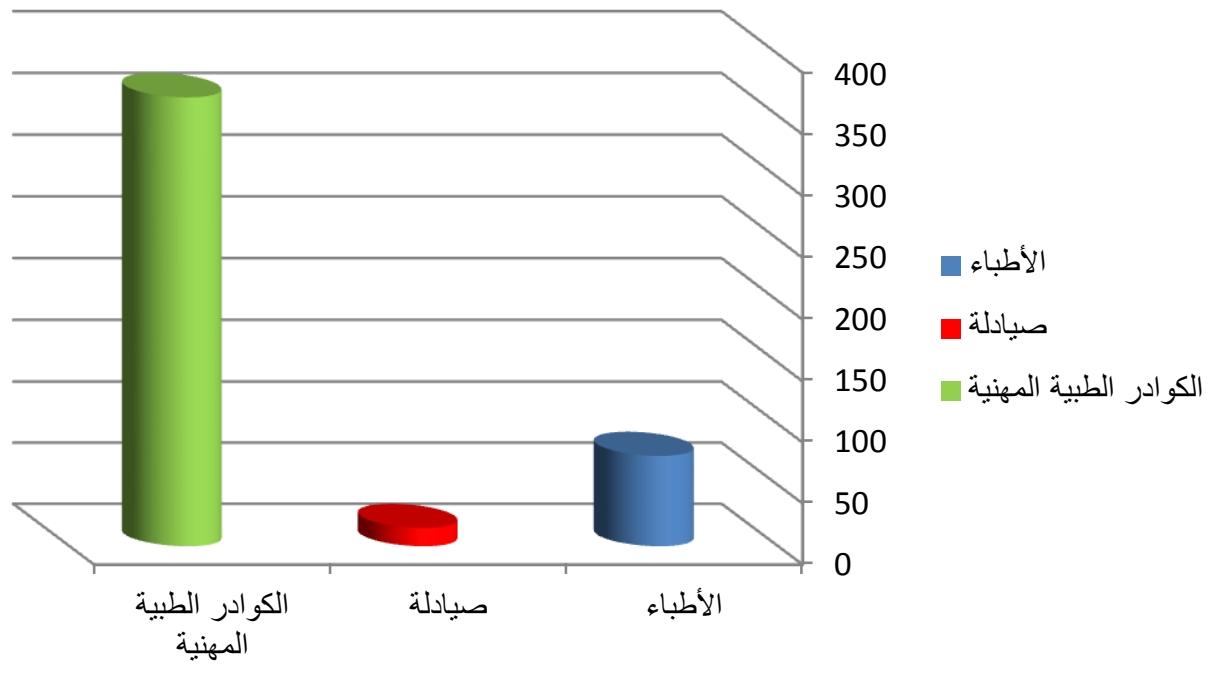


شكل (r)

مجلــــة كليـــة التربيـــة عدد الاطباء والصيادلة والكوادر الطبية المهنية للمركز الصحية في مدينة الزبير لعام

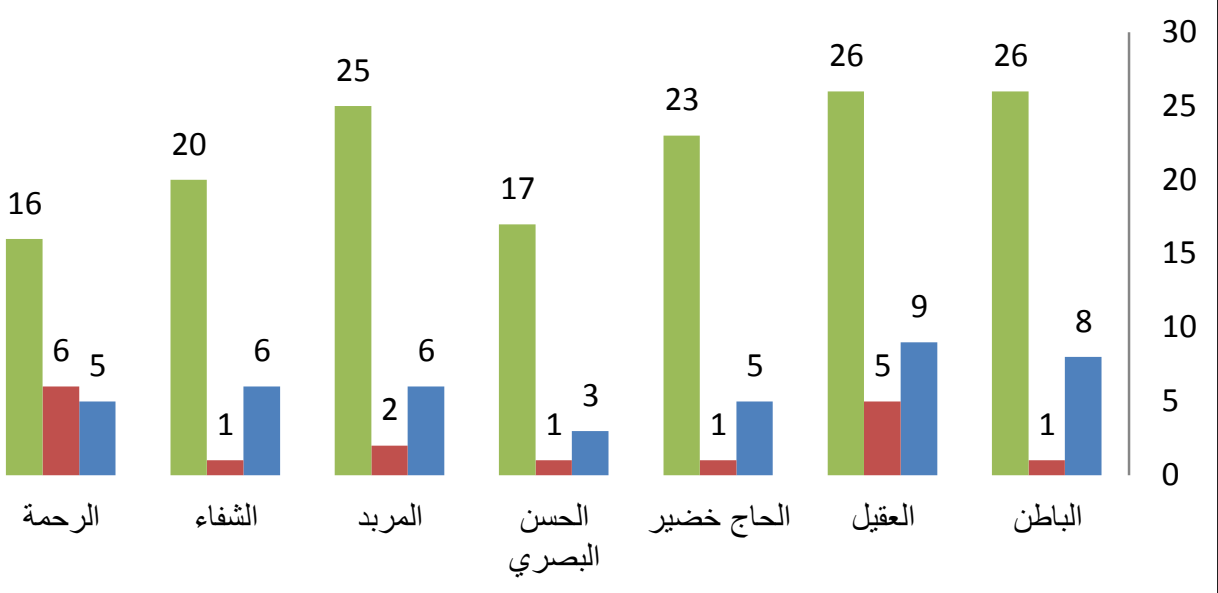

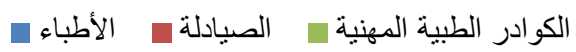

شكل (r)

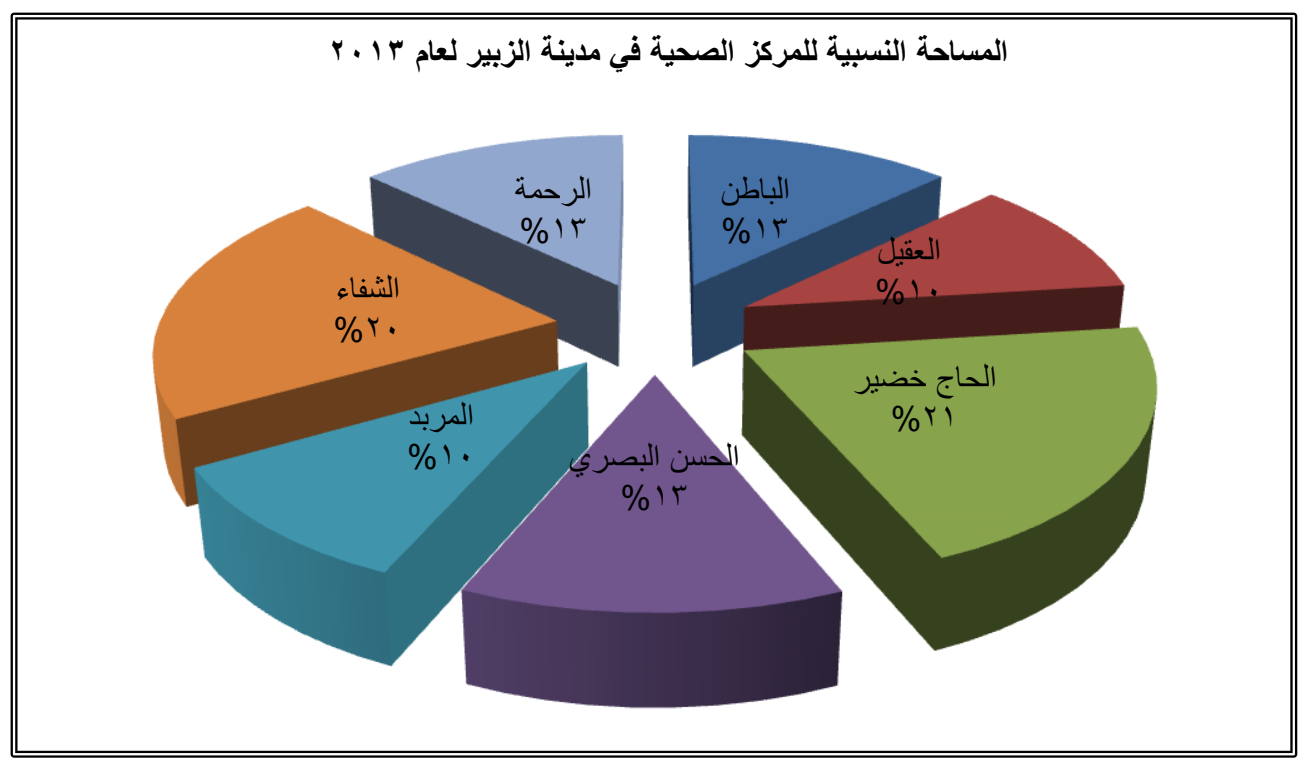

居 
شكل (๕)

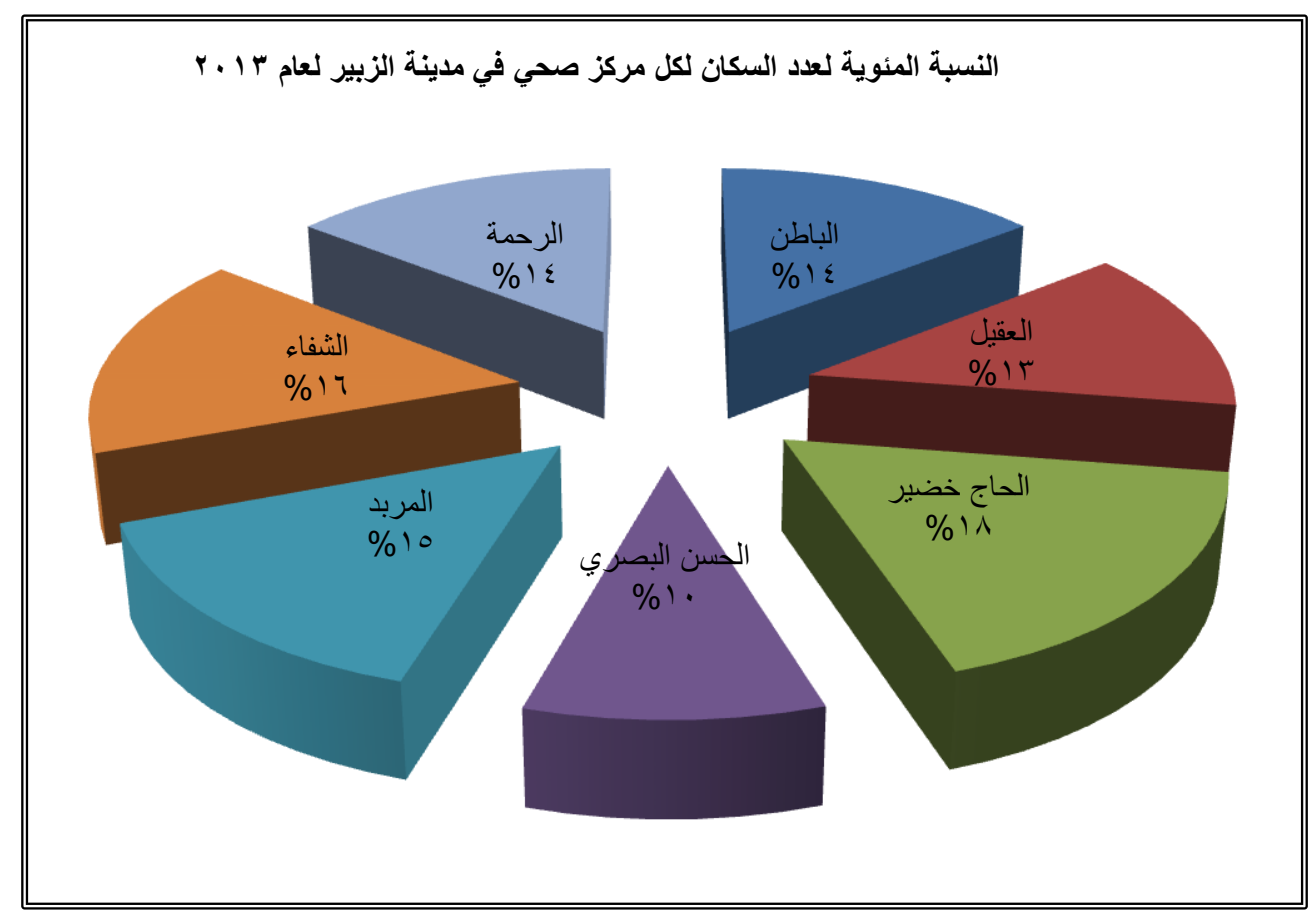

المصدر : الباحثة بالاعتماد على جدول رقم (1 و

المصدر : الباحث بالاعتماد على جدول (ץ)

وبالرجوع إلى الجدول (Y) والثكل (Y، r ، ع) يتبين أن مدينة الزبير تضم (V) مراكز صحية

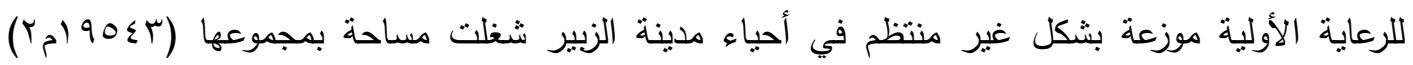

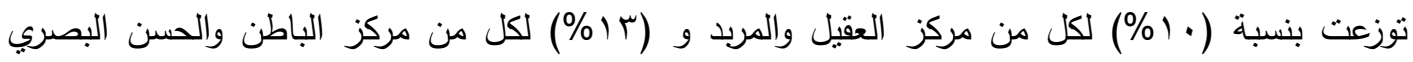

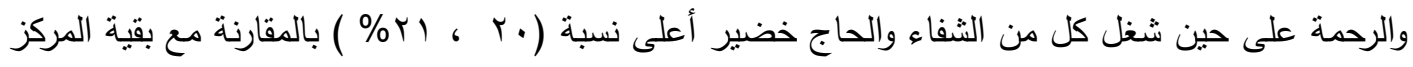

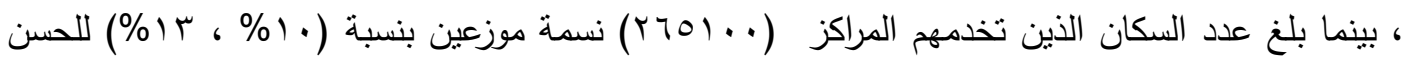

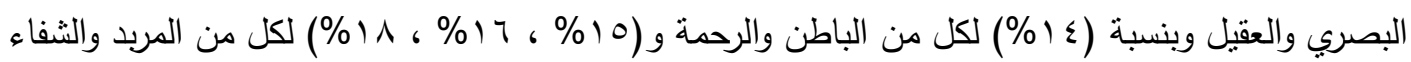

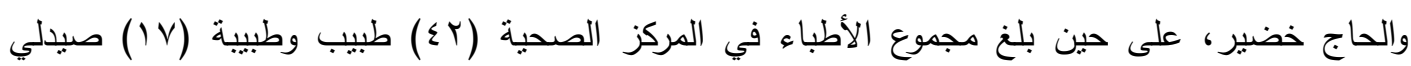
و(10 إ) من الكوادر الطبية المهنية. 


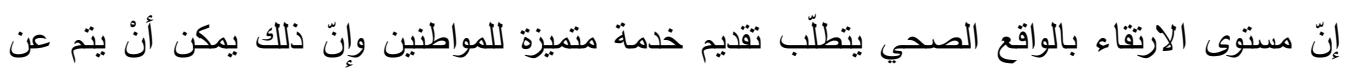

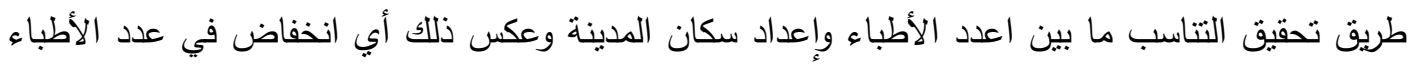
بالنسبة لإعداد السكان يؤدي إلى تدني مستوى الخدمات الصحية التي تقدم للسكان وبدوره سوفه ينعكس على الصى

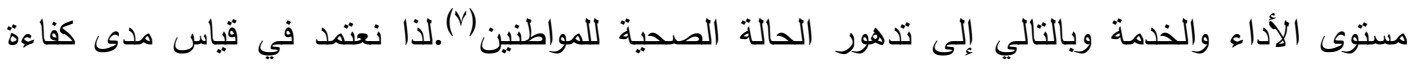
الخدمات الصحية للسكان بالاعتماد على المعايير العالمية والمحلية لكي ينسنى المقارنة وإيجاد الحلول المناسبة.

$$
\text { 1 - معيار طبيب / شخص }
$$

إنّ وزارة الصحة في العراق قد وضعت معيارها على أساس (طبيب/· ... إنسمة) وفي مدينة الزبير

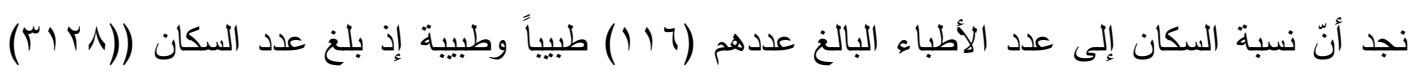
نسمة لكل طبيب ولهذا فهي أعلى من المعيار وتكون هذه النسبة غير مقبولة قياساً بالمعيار المحلي.

$$
\text { r- r - معيار صيدلي / شخص }
$$

وحسب المعيار المحلي في العراق بلغ المعدل لهذا المعيار صيدليًا واحدًا لكل ( (...... نسمة.

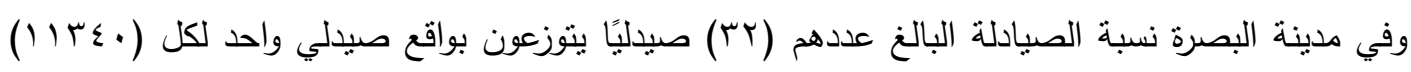
نسمة وهو أقل من المعيار ويسدً حاجة سكان المدينة من هذه الخدمة لوجود عدد كاف من الصبيادلة. r- معيار ذوي المهن الصحية / طبيب حدد المعيار العالمي بضرورة نوفر ثلاث من ذوي المهن الصحية لكل طبيب في مدينة الزبير، بلغ عدد ذوي المهن الصحية (1) 10 وهم يمنلون (ع) لكلّ طبيب وهو أعلى من المعيار المعتمد. 
اعتمدت وزارة الصحة معيارًا يمثل مهني واحد لكل (..ع-...0) شخص وعند تحديد واقع هذا المعيار في المدينة بمعدل مهني واحد لكل (V... وهو أعلى من المعيار ولهذا فهو لا يسد حاجة المدينة من هذه الخدمة.

0- المعايير المساحية للمؤسسات الصحية لمدينة الزبير ترتبط الكفاءات كذلك بالمساحات التي تثغلها المؤسسات الصحية بما ينطبق مع التخطيط الحضري

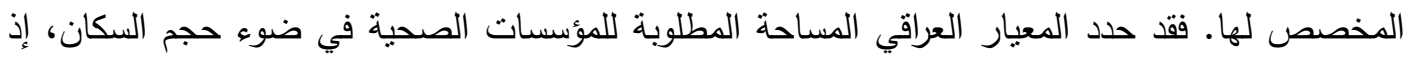

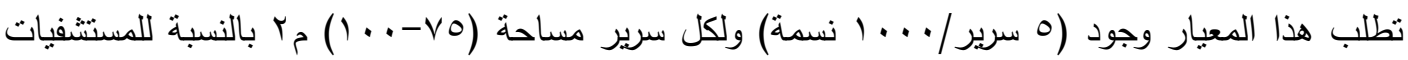

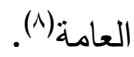
أ- مساحة المستشفيات

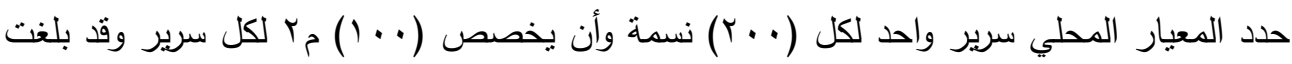

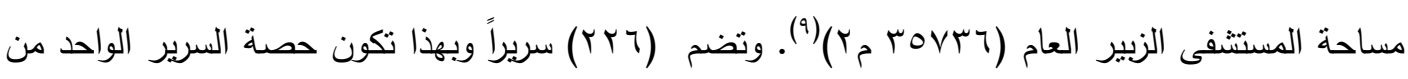
المساحة (101) مج وهي أعلى من المعيار المحلي وتوفر فائض من المساحة. أما عدد الأسرة مقارنة بعدد

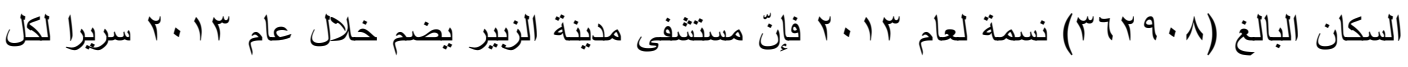
(17.0) نسمة وهو أعلى من المعيار المحلي فإنّ المدينة بحاجة إلى عدد إضافي من الأسرة المطلوب توفيرها لسد حاجة سكان مدينة الزبير وتبلغ (1011) سريراً وتتطلب مساحة داخل المستشفيات مقدارها

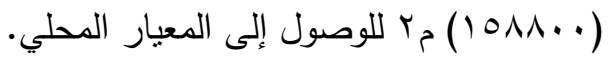


حدد المعيار المحلي أن يخدم المركز الصحي الواحد (...... (1) نسمة وفي مدينة الزبير بلغ عدد

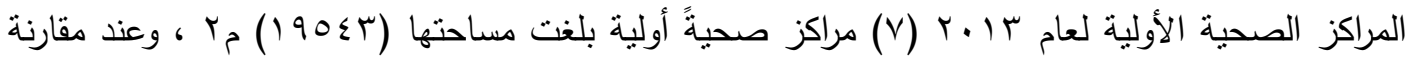

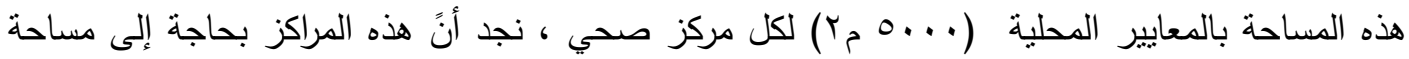

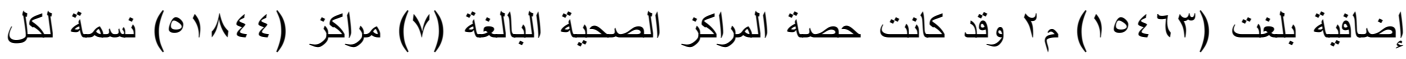

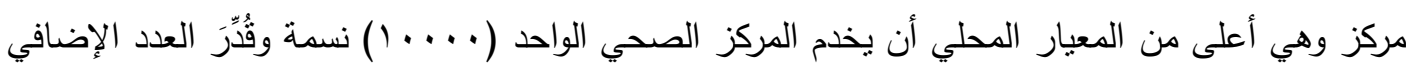

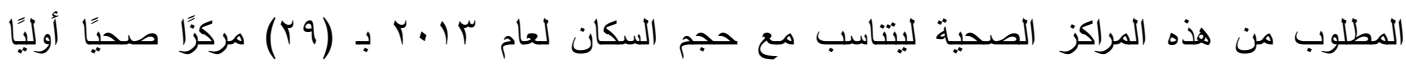
وتخصيص مساحة إضافية لها بواقع (...

\section{7- معيار سهولة الوصول}

هو أحد المؤشرات المهمة لقياس كفاءة الموقع للمؤسسات الصحية، وقد عده صفة سهولة الوصول إلى المؤسسات الصحية عن مدى كفاية الدعم للرعاية الصحية الأولية. حدد المعيار المحلي ضرورة نوفر

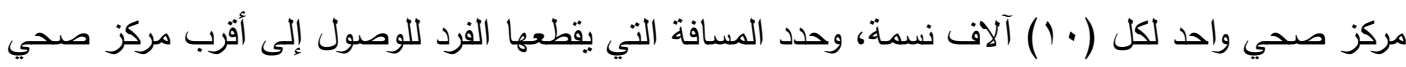

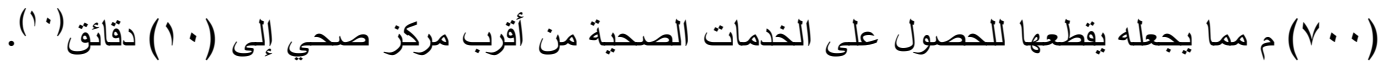
وفي مدينة الزبير نلاحظ 17,7 \% من محلات منطقة الزبير تقع ضمن المسافة المريحة وهي كل من محلة الجمهورية الأولى ، الرشيدية الثانية ، العسكري ، وبعض الأجزاء الدحدودة جداً كمحلة الجمهورية

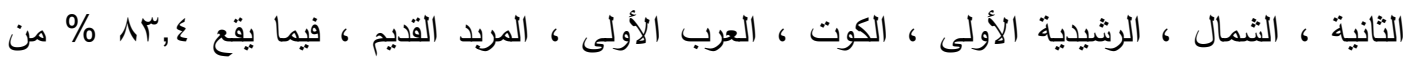
المحلات خارج المسافة المريحة وهي تمثل بقية محلات منطقة الدراسة. 
نستتنج من خلال البحث أنّ هناك مشاكل في الخدمات الصحية في المدينة مما ينطلب من القائمين بعمليات التخطيط الصحي معالجتها وتضمن:

$$
\text { 1- بلّة النفقات الموجهة لهذه الخدمة }
$$

r- عدم تطور مؤسسات الخدمات الصحية بما يتفق والنمو السكاني مما يولد ضغطاً على القائم منها فيقلل من كفاءة عملها فينعكس ذللك سلباً على صحة الإنسان. r- عدم توافر أعداد كافية من الأطباء في التخصصات المهمة وان توافرت سيركز وجودها في المستثفى الرئيسي فقط مما يجعل الحصول على خدمات تلاك التخصصات غير مناح في مناطق الأخرى، أو يدفع بعض السكان إلى سفر داخل أو خارج القطر ولاسيما إلى إيران والهند والأردن طلباً للعلاج مما يزيد من تكاليف العلاج وعناء السفر ولاسيما فيما يخص الأثخاص كبار السن أو محدودي الدخل. ع- عدم توافر الثقنيات الحديثة في معظم المؤسسات الصحية، أو عدم توافرها في البلا وهذا يقلل من كفاءة أداء الخدمات الصحية إذ إنّ استعمال الأجهزة المنطورة يقلل من المخاطر التي يتعرض لها المريض. ه- عدم تطوير الكادر الطبي والإداري والفني بما ينسجم والتطورات التكنولوجية والتقنية التي يشهدها العالم. 1- قلّة خبرة بعض العاملين في المختبرات والأشعة والسونار مما يجعل عملية تشخيص الحالة غير صحيحة، ومن ثم يعطى علاجاً للمريض غير ملائم فتكون النتائج عكسية ويلحق بالمرضى الأضرار. 
1- Elliot, K. M. and Healy, M. A. (2001), "Key factors influencing student satisfaction related to recruitment and retention”, Journal of Marketing for Higher Education, Vol.10, No.4: 1-11.

r- علاء عبدالكريـم البلداوي، قياس كفاءة جودة خدمات المراكز الصحية في محافظة كربلاء باستخدام

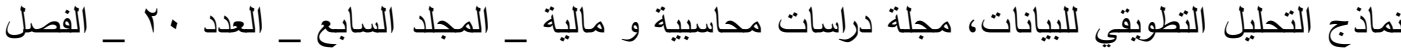

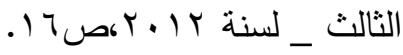

-r-r عدمان مريزق، "واقع جودة الخدمات في المؤسسات الصحّية العمومية، د ا رسة حالة المؤسسات الصحية في الجزائر العاصمة"، أطروحة مقدمة لدحصول عمى شهادة دكتوراه في عموم التسيير، جامعة

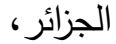

4 - اد. مندور، أحمد محمد _ د. نعمة الله، أحمد رمضان، 1990 " اقتصاديات الموارد والبيئة " مؤسسة شباب الجامعة ،هصر العربية ،ص عبr

-0 د. عبيدو، محمد، سج991 " مدخل إلى التخطيط الصحي الاقتصادي " وزارة الثقافة، دمشق، ص 11. -7 - -امال صالح عبود ،عبدله سالم عبداله، مؤشرات ومستويات انتفاع السكان من التسهيلات الصحية في

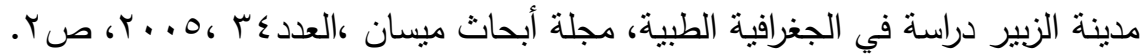
V- نبيل جعفر عبد الرضا، البيئة الاستثمارية في البصرة المحدات والتطلعات، طا، مؤسسة التاريخ

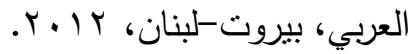

^- وزارة التخطيط، هيئة التخطيط الإقليمي، قسم الإسكان والمستوطنات البشرية ومعايير مباني الخدمات

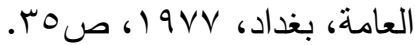

9- دائرة صحة البصرة ،مستشفى الزبير العام ، شعبة الإحصاء، بيانات غير منشورة با ـ ؟.

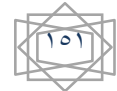


• 1- صلاح مهدي عريبي الزيادي، تقويم الكفاءة الصحية في قضاء القرنة، مجلة آداب البصرة، العدد

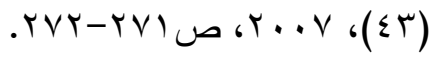

